\title{
Comparative Stratification and Mobility
}

\author{
ALBERT A. SIMKUS \\ The University of Michigan, Ann Arbor, U.S.A.
}

SOCIAL INEQUALITY invites comparisons. If inegalitarian social orders are justified by arguments that inequality is functionally necessary or inevitable, the existence of egalitarian societies challenges the legitimacy of such orders. In general, the issue involves matters of degree. How much inequality is necessary? How great are the tradeoffs between equality and aggregate benefit in calculations of social justice? For those who benefit from inequalities and those who wish to decrease them, cross-societal comparisons of social stratification promise instruction by example.

Unfortunately, while cross-national comparisons are common in lay political rhetoric, comparative research on stratification has been less abundant. Much of what we know is based on analyses of crude data of questionable comparability, secondary analyses of data whose methodological bases are poorly documented, and impressionistic contrasts between studies of individual societies. Edited volumes and conferences dealing with "comparative stratification" often involve collections of studies of individual societies, with editors, discussants, and audiences left to draw comparative conclusions. This situation is not due to laziness on the part of students of comparative stratification. The difficulties and costs of primary comparative research place great constraints on collaborating researchers and greater constraints on individuals. Fortunately, increasing collaboration between groups of primary researchers, combined with the diffusion of research interests and methodological conventions, has resulted in progress in our ability to describe and explain comparative differences in stratification and mobility.

In the late $1960 \mathrm{~s}$, the agenda for comparative research on social stratification was influenced by the research traditions of the preceding period, the theoretical issues then attracting attention, and various methodological innovations. Among the more prominent topics of research during the previous decade were studies of comparative differences in occupational prestige and differences in rates of social mobility. In general, the work in these areas suggested that occupational prestige hierarchies and patterns of social mobility are similar in modern industrial societies, confirming arguments about the func- 
tional basis of stratification, requirements of industrial societies, and crossnational convergence. Due to the considerable time lag usually involved between the planning of national surveys and the publication of cross-national comparisons based on secondary analyses of the national data, the concerns and methods of the early 1960s have largely determined the nature of comparative research on prestige hierarchies and social mobility over the succeeding decade and a half. In both of these areas, work continued during the $1960 \mathrm{~s}$ and $1970 \mathrm{~s}$, based on the earlier theoretical and methodological assumptions, but making use of data of improving quality from a growing number of societies.

Over the last couple of decades, quantitative comparative research on stratification generally followed a deductive strategy, seeking to confirm hypotheses drawn from the "functionalist" and "industrial society" literatures (see Treiman, 1970; and Goldthorpe, 1964), and from Lenski's (1966) influential Power and Privilege. Lenski's work provided an elaborate synthesis of functionalist, conflict, and developmental approaches to stratification. However, the impossibility of empirical tests of Lenski's complete argument led to tests in which Lenski's thesis was often reduced to a simple model of technological determinism, stressing those notions it shared with the "industrial society" and "convergence" theses. Much research simply concentrated on examining the cross-national association between measures of economic development and degrees of inequality.

Another group of comparative studies was concerned with the consequences of differences in political and economic organization. Some of these examined the relationship between political democracy and equality-also part of Lenski's thesis - while others considered the impact of social-democratic political influence on various aspects of stratification (Parkin, 1971; Hewitt, 1977). Still other studies compared East-West differences in European social stratification, assessing the consequences of socialist social organization in those existing forms of socialist states for which data have been available (Lane, 1971, 1976; Parkin, 1969, 1971; Pryor, 1968, 1971, 1972, 1973; Connor, 1979).

The methodological innovations influencing comparative research during this period included the development of scales of occupational prestige and synthetic scales of general socioeconomic status, the employment of such scales in structural equation models of the process of status attainment, and the use of multiplicative models of contingency tables to analyze comparative differences in social mobility. Having first been introduced in the analysis of stratification in individual countries, each of these approaches was extended during the 1960 s and 1970s to the analysis of comparative data. By far the most active areas of research involved comparisons of income distributions, occupational prestige hierarchies, and rates of social mobility.

Comparative research dealing with the relational, as opposed to the distributional, aspects of social stratification was rare. Comparative research 
on the consequences of stratification was likewise relatively uncommon. This review concentrates on explicit cross-societal comparisons of occupational prestige and social mobility - two of the areas in which comparative research in stratification has been most extensive. Comparative studies of income inequality are discussed elsewhere in this volume (see the review by Isaac). The lack of attention given comparative research on class relations, such as the important work done by Paige (1975) and Tilly et al. (1975), is hardly meant to minimize its importance. There are simply so few such studies that a survey review is less useful.

\section{Cross-National Differences in Occupational Prestige}

The series of international studies of occupational prestige (see Armer, 1968; Harris, 1968; Jakubowicz, 1968; Teckenberg, 1977) culminated in the publication of Treiman's Occupational Prestige in Comparative Perspective (1979). This book was important for several reasons: It provided a fully developed statement of the arguments associated within this tradition of research; it presented and analysed an impressive collection of prestige surveys for 60 societies; and it made available a Standard International Occupational Prestige Scale (SIOPS) as a potential tool in future comparative research on social stratification and status attainment.

Treiman presented a "structural theory of prestige determination," which argued as follows: The functional requirements of modern societies demand a division of labor involving differences in authority and skill. Differences in authority and skill inevitably involve differences in power, which in turn give rise to differences in privilege and prestige. Since modern societies require similar structural divisions of labor, prestige hierarchies are expected to be essentially the same everywhere.

This argument was defended on the basis of several forms of evidence. First, since the average correlation among prestige scales in Treiman's set of countries was .81 , it was argued that prestige does not reflect cultural idiosyncrasies. The notion that the cross-national uniformity in prestige rankings is due to cultural diffusion was discredited by pointing out that education, income, and prestige are consistently highly correlated in those societies for which data on all three are available. If prestige evaluations alone diffused from the Western industrial societies, we would not expect these correlations to be high; however, we are still left with the possibility that occupational differences in education, income and prestige diffused together from the West as an integrated system of economic organization. Treiman pointed out that occupational hierarchies in wealth in six societies during the fifteenth through nineteenth centuries, as well as hierarchies in prestige in 14th century Nepal and 15 th century Florence, show a correlation of about .7 with his contemporary SIOPS scale, suggesting that this occupational hierarchy did not simply diffuse from modern industrial societies (Treiman, 1976; 1979). Finally, 
Treiman argued that prestige hierarchies in the socialist countries of Eastern Europe and in rural samples in underdeveloped countries are "exceptions which prove the rule." The somewhat lower correlations between the prestige ratings derived from the latter samples and the SIOPS scale were taken as further evidence that similarities in prestige hierarchies derive from similarities in occupational structure, since the discrepancies involving these samples were attributed to underlying differences in structure.

The SIOPS scale, based on the average ratings of each occupation in the nations for which prestige estimates were available, promises to be a useful tool for comparative research. If such prestige ratings are universally similar, the use of a standard scale would simplify the problem of reducing comparative differences in stratification to a common dimension with a common metric. Furthermore, the SIOPS scale could be used as a continuous scale of general social status even in those societies where data on occupational prestige evaluations, income, and education are unavailable. Clearly, part of the motivation for the development of such a scale was the need for a metric scale of socioeconomic status which could be employed in comparative studies of the process of status attainment (see Treiman, 1975, 1977; and Jones and McDowell, 1977). The role of the SIOPS scale in facilitating comparative status attainment research is analogous to the role of the Duncan SEI scale in facilitating the estimation of status attainment models for the United States (Blau and Duncan, 1967). Such applications of the SIOPS scale in crossnational research have already begun (Treiman and Terrel, 1975).

In a partially favorable review of Treiman's (1979) book, Haller and Bills (1979) re-examined Treiman's data and criticized a number of his conclusions. They argued that Treiman's conclusion that there is only one occupational prestige hierarchy is overstated and premature. Haller and Bills pointed out that $15 \%$ of the cross-sample comparisons of prestige ratings involved squared correlations of less than .5 , and an additional $22 \%$ of the possible comparisons involved too few common occupational titles to allow valid contrasts. They also pointed out that Treiman's correlations between education, income, and prestige were based on only a small subset of his sample of countries, that considerable measurement error was involved in the case of agricultural occupations, and that the sample of societies included was somewhat restricted. They further observed that the roles of power and conflict in the determination of prestige can only be presumed, since the data do not include measures of power.

In their reanalysis of the data, Haller and Bills found that the dissimilar national prestige rankings were systematic; the scales for the socialist countries were similar to each other, but dissimilar to those for non-socialist countries. Furthermore, scales from industrial societies and urban samples were more consistent than those from less developed countries and rural samples. They concluded that a universal prestige hierarchy may apply within the set of modern urbanized societies, but that outside of this set of societies there may be 
significant variation. They suggest that other scales of socioeconomic status should be used along with the SIOPS, and that such scales may do a better job of explaining status attainment and other stratification-related processes.

Additional problems with this line of research may also be pointed out. While the ordinal nature of occupational prestige scales of this kind is acknowledged, it tends to be underemphasized. The method by which each national scale is produced does not establish the degree of differences in prestige-only differences in ordinal rankings, yet the degree of differences in prestige is surely one of the most important aspects of prestige hierarchies. It is misleading to maintain that occupational prestige hierarchies are universally similar if occupational differences in prestige are trivial in some societies and awesome in others. Cross-national differences in the procedure of rating occupations, as well as cross-cultural differences in the interpretation of the ranking task, make the interpretation of degrees of differences in prestige scales difficult. Standardizing such scales to a common mean and variance does not solve the problem of what a difference of $\mathrm{X}$ points in two prestige scales means. In some ways it complicates it. Perusing Treiman's tables of deviations of national prestige scores for individual occupations from the corresponding SIOPS scores yields numerous apparently significant deviations, some invitingly interpretable and others merely intriguing. It is too easy to forget that the substantive meaning of these deviations is unclear.

Furthermore, arguments concerning the universality of a hierarchy of occupations are to some degree, tautological. A hierarchy is implied in both the titles of positions and, more subtley, in the process of classifying culturally specific positions into a standard occupational scheme. It is not surprising that "high administrative officials" have relatively high status in most societies. Notions of prestige are bound up with the title of the position; and, in those societies where such high officials are despised by the population, they are unlikely to permit publication of prestige surveys advertising the fact. Of course, not all occupational titles are so obviously inseparable from the concept of general social standing. Still, it is easy for certain implicit status distinctions to affect the definition of "functionally equivalent" occupational positions in different societies, and this may contribute to the cross-national similarities in hierarchies after these hierarchies have been reduced to a standard set of categories.

Finally, while the SIOPS scale may prove very useful in various circumstances, caution does seem advisable in relying on it as the only indicator of the socioeconomic status hierarchy in any given society. While the average correlation between the SIOPS scale and the national prestige scales is high, from one-tenth to one-half of the variance in a given national scale is likely to be untapped by the standard scale. Thus, cross-national differences in status attainment models utilizing the SIOPS scale may reflect differences in status hierarchies rather than differences in the transmission of status. This problem may be most serious when the occupational distributions of particular societies 
are concentrated in positions whose prestige does not conform well to the standard scale.

These comments should not detract from the importance of Treiman's contribution nor from that of the researchers upon whose primary research Treiman depended. This body of work represents an almost unique example of the accumulation and analysis of comparable survey data related to stratification in a large number of diverse societies. Our ability to progress from speculation to measurement in the comparative analysis of social stratification requires similar efforts in other areas, necessitating both cooperation in standardizing measurement procedures and cooperation in making results available for comparative secondary analyses of pooled international data.

\section{Cross-National Differences in Social Mobility and Status Attainment}

The most active area of comparative research involved comparisons of national rates of social mobility (see Matras, 1980; Boyd et al., 1981; Broom and Jones, 1969a, 1969b; Broom and McDonell, 1974; Garnier and Hazelrigg, 1974; Hansen, 1977; Jones, 1976; Kleining, 1978; McRoberts and Selbee, 1978; Moots, 1976; Pontinen, 1976; Svalastoga, 1965; Svalastoga and Rishoj, 1970; Wesolowski et al., 1978). The proliferation of comparative mobility studies resulted from the increasing number, quality, and comparability of national social mobility tables available for secondary analyses, and also from a series of methodological contributions which steadily increased the sophistication of means of separating structural from other-than-structural components of cross-societal differences in mobility (see Cutright, 1968b; Hauser et al. 1975; Hauser, 1977).

Unfortunately, until recently there was little improvement in the level of aggregation involved in the mobility tables compared. The great majority of comparisons were based on simple $3 \times 3$ intergenerational social mobility tables, classifying sampled respondents on the basis of their fathers' social stratum and their own social stratum, according to a trichotomous distinction between nonmanual, industrial-manual, and agricultural occupations. Comparisons based on more detailed social categories involved considerable sacrifices either in accuracy or in the number of societies compared. There were virtually no comparisons in which respondents were compared within categories of age or year of birth (for an exception, see Andorka and Zagorski, 1979), and few cases of comparisons based on samples of females.

Changes in the statistical measures used in comparative studies of mobility involved partial abandonment of inflow and outflow percentages and the increasing application of various indices of "circulation mobility," "exchange mobility," or "openness," in order to measure differences in movement across social stratum boundaries net of differences in the distributions of social strata (Yasuda, 1964; Boudon, 1973). Canonical correlations between sets of discrete categories of social origins and destinations were also used in such com- 
parisons, both as a way of removing some forms of structural differences from comparisons of circulation and also as a way to produce a scale of differentation between socio-occupational categories based on patterns of intergenerational association in social status (Featherman et al., 1975). In those cases where comparable scales of socio-economic status for two or more countries were already available, status attainment models could be used to compare more sophisticated descriptions of the process of intergenerational transmission of social status (Jones, 1971; Kerckhoff, 1974; Treiman and Terrell, 1975). Queuing models of mobility explored a quite different approach to modeling aspects of the process of mobility, allowing simulations of the ways changes in the distributions of social strata and individual attributes may cause-or not cause-changes in the degree of intergenerational association in status (Boudon, 1974; McCann, 1977).

The application of various multiplicative models of mobility tables allowed increasingly elegant means of separating structural from other-than-structural differences in mobility, and of examining differences in particular aspects and patterns of association in mobility tables (Goodman, 1969, 1972, 1979; Pullum, 1975; Hauser et al., 1975; Hauser, 1977; Duncan, 1979). Contrasts between certain national mobility tables became virtually a standard means of introducing new ways of parameterizing the frequency distributions in contingency tables. Unfortunately, the number of different analyses involving a famous pair of British and Danish mobility tables has not been matched by an equal number of sociological insights into differences in mobility between these two societies. At the same time, comparative applications of methodological advances in the analysis of mobility tables have sometimes lagged behind the rate at which such developments have been introduced.

One new aspect of the methodology of such comparisons in the late 1960s involved multivariate analyses of cross-national differences in mobility rates, utilizing nations as cases (Cutright, 1968a; Hazelrigg and Garnier, 1976; Tyree et al., 1979; McClendon, 1980a). Generally, the small number of cases involved precluded legitimate analyses exploring the simultaneous effects of more than a couple of independent variables. Still, this approach improved the accuracy of descriptions of the cross-national variation in mobility-at least in that set of countries for which data were available.

In reviewing this body of research, it will be useful to organize the discussion in terms of the primary hypotheses with which these studies were preoccupied. More specifically, these studies will be divided into two groups: First, those at least partly concerned with the effects of industrialization or the supposedly universal requirements of industrial societies; and second, those concerned with socialist-non-socialist differences. In order to better describe the evolution of this line of research, we will begin with the studies published in the early 1960s.

It will also be useful to at least temporarily adopt precise definitions of a number of terms which, when used more loosely, have resulted in some confu- 
sion over the relationships between various mobility indices and substantive aspects of mobility. By "structural" differences in mobility, we shall mean all differences which can be attributed to any form of effect of the univariate distributions of social origins and destinations. Such structural differences include 1) "discrepancy effects" of structure-effects of discrepancies between the distributions of social origins and destinations, as indicated by "forced mobility" or the index of "structural mobility," and 2) "compositional effects" of structure-effects of the relative sizes of particular social strata typically characterized by particularly high or low degrees of status inheritance (see Simkus, 1980; McClendon, 1980a, 1980b). "Other-than-structural" or " non-structural"' differences in mobility shall refer to differences in the patterns of association in mobility tables, as indicated by differences in odds-ratios, odds-ratio-related mobility indices, or distribution-free measures of association.

By differences in "mobility" we shall mean differences in the proportion of persons mobile, regardless of their source. Differences in the amount of mobility back and forth across stratum boundaries which cannot be attributed to either form of structural effects will be referred to as differences in "openness." Finally, differences in mobility due to a combination of both compositional differences and differences in openness, but not due to structural discrepancy effects, will be referred to as differences in "circulation."

\section{Social Mobility and Industrialization}

Due to the paucity of long-term longitudinal data, most research explicitly directed at examining the industrialization-mobility relationship has involved cross-sectional comparisons of nations at different levels of industrialization and economic development. If the industrialism thesis is correct, the longitudinal relationship between industrialization and intergenerational mobility is more or less the same in all nations; and, cross-national differences at a given time simply reflect different positions along the common longitudinal course of development. However, while the absence of a crosssectional relationship between levels of industrialization and mobility may disconfirm the industrialism thesis, the presence of such a relationship in a cross-section does not prove that the longitudinal relationship holds. Nevertheless, the dearth of national longitudinal data spanning wide differences in levels of industrialization has forced those interested in the industrializationmobility relationship to turn to the cross-sectional evidence by default.

The series of cross-national comparisons directed at evaluating the industrialization-mobility thesis began with Lipset and Zetterberg's (1957) paper, "Social Mobility in Industrial Societies." This early comparison examined intergenerational mobility between the manual and nonmanual strata in the urban populations of six industrialized nations. Lipset and Zetterberg concluded that all these industrialized countries displayed relatively uniform high rates of total mobility $(23 \%-31 \%$ mobile). 
When total mobility was divided into upward and downward mobility, larger cross-national differences were observed. While the rates of upward mobility were still roughly similar, the downward rates showed significant differences; however, Lipset and Zetterberg were reluctant to interpret these differences, since they formed no obvious pattern and were based on data of questionable reliability.

Since their data contradicted the then popular notion that total mobility was much greater in the "open" United States, as opposed to the presumably more "closed" European nations, Lipset and Zetterberg were most impressed with the lack of cross-national variation' in their data. This impression of uniformly high mobility rates among industrialized nations was consistent with the industrialism and convergence theses; yet, it could only be assumed that mobility rates were much lower in the less industrialized nations for which there were no reliable data. Furthermore, small differences in levels of industrialization, such as existed between the countries in this sample, were not seen as having significant effects on mobility. The diffusion of interest in national surveys of intergenerational social mobility, and opportunities for collaboration provided by the International Sociological Association, led to a pool of national mobility tables which constantly increased in number and comparability (Featherman, et al., 1974). Comparisons based on better data soon superseded the work of Lipset and Zetterberg, and later reexaminations of their original data concluded that the problems of reliability and comparability in these data were so great as to render these comparisons worthless (Jones, 1969).

The next extensive cross-national comparison was that presented by S. M. Miller (1960), based on fifteen national surveys for thirteen countries and urban and special samples for an additional five countries. Miller rejected the notion that a country which is high in one form of mobility is likely to be high in all other forms of mobility as well. Consequently, he concentrated on comparing specific rates of mobility, namely, manual into nonmanual, nonmanual into manual, lower nonmanual into upper nonmanual positions, and several similar rates. He also compared tables on the basis of indices of association in the mistaken belief that they removed the effects of differences in structure (see Hauser et al., 1975).

Miller's (1960) primary conclusion was that different forms of mobility are not positively associated across countries. In fact, some rates, such as manual to nonmanual and nonmanual to manual mobility, tend to be negatively associated. With our present more sophisticated understanding of the effects of structure on inflow and outflow mobility rates, this finding is no surprise. Those aspects of structure which tend to increase upward mobility (namely, high proportions of persons in "higher" positions) necessarily tend to decrease downward mobility.

Miller did not strongly dispute Lipset and Zetterberg's (1957) conclusion that manual to nonmanual rates were similar and high in all industrialized 
countries. However, he suggested that it was debatable whether or not the rates were so similar as to be characterized as uniform. Furthermore, there was clear variation across countries in regard to forms of mobility other than manual to nonmanual mobility. Miller (1960) classified the countries for which he had data on the basis of their profiles of different types of rates; however, in this early paper he did not elaborate upon generalizations which might explain these cross-national differences.

In later papers, Fox and Miller (1965a; 1965b) examined the association between intergenerational social mobility rates and a number of social and economic variables, utilizing the twelve national mobility tables studied earlier by Miller (1960). They found mobility from manual origins into the nonmanual stratum to be positively associated with per capita GNP, primary and secondary school enrollment, political stability and democracy, urbanization, and achievement motivation-the strongest relationship being that with school enrollment rates. The outflow rate from nonmanual origins into the manual stratum was negatively associated with per capita GNP, school enrollment rates, and achievement motivation, and positively associated with political stability and urbanization. In general, the relationships involving nonmanual to manual mobility were less strong than those involving manual to nonmanual mobility. Fox and Miller (1965a) concluded that there were considerable differences in mobility among these countries; and, that "although economic factors are important, they are not uniquely significant in influencing mobility patterns."

The strongest relationships reported by Fox and Miller were almost certainly influenced by cross-national differences in structure. Per capita GNP and rates of school enrollment are positively associated with the size of the nonmanual stratum and the size of the nonmanual stratum greatly affects the chances of persons from any stratum entering the nonmanual stratum. Furthermore, since the manual stratum in Fox and Miller's comparison included agricultural manual workers, and since per capita GNP and school enrollment would tend to be negatively associated with the size of the broad manual stratum, it is easy to see why GNP and enrollment would be negatively associated with outflow rates to the manual stratum. Fox and Miller's analysis showed the degree to which GNP and school enrollment are associated with observed mobility, but did not show to what extent these relationships were due to structural differences in mobility. In contrast, subsequent cross-national comparisons attempted to make use of statistics which eliminated, or at least isolated, the effects of differences in structure.

In his comparison of intergenerational mobility tables for thirteen countries, Cutright (1968a) used Yule's $Q$ as an index of status inheritance. In some of his comparisons, "total Q" was calculated from $2 \times 2$ tables classifying respondents and their fathers on the basis of having manual (including agricultural) versus nonmanual occupations. For a smaller set of countries, "non-farm Q" was also calculated from $2 \times 2$ tables excluding manual 
workers in agriculture. Thus, the cross-national differences in total $Q$ and nonfarm $Q$ were not sensitive to structural discrepancy effects. However, total $Q$ was subject to substantial compositional effects related to the proportion of manual workers in agriculture; more specifically, the higher the proportion in agriculture, the higher the likely value of total Q (McClendon, 1980b).

In Cutright's set of mobility tables, per capita energy consumption, urbanization, and the extent of mass communications were all negatively associated with both non-farm $Q$ and total $Q$. As would be expected due to the aforementioned compositional effects, the associations involving total $Q$ were significantly greater than those involving non-farm $Q$. Industrialization and economic development would seem to increase mobility both by increasing openness between the urban manual and nonmanual strata and by increasing total circulation through decreasing the size of the agricultural labor force.

Comparisons of mobility across the manual-nonmanual boundary ignores mobility between the agricultural manual and industrial manual occupations. Hazelrigg (1974) compared mobility measures calculated from intergenerational $3 \times 3$ mobility tables, based on the nonmanual / industrial manual / agricultural manual distinction. In his set of ten national tables, derived from surveys conducted during the 1950 s and early 1960 s, he found a positive relationship between national energy consumption and rates of circulation. Although he reported the relationships to be insignificant (statistically insignificant, due to a sample size of 10 ), his data showed a moderate positive correlation between energy consumption and both total mobility and upward mobility.

The next set of such cross-national comparisons was carried out by Hazelrigg and his collaborators (Hazelrigg and Garnier, 1976; Hardy and Hazelrigg, 1978), making use of a larger and more reliable set of mobility tables than had previously been available. These comparisons involved $3 \times 3$ mobility tables from national surveys conducted in seventeen countries during the 1960 s and early 1970 s. The three social strata across which mobility was measured were defined as in Hazelrigg's previous study (Hazelrigg, 1974). These comparisons examined the relationship between a number of independent variables and two measures of mobility: 1) "circulation I," total mobility calculated from tables whose destination distributions were standardized to equal their origin distributions and 2) "circulation II," total mobility calculated from tables standardized to equiproportional origin and destination distributions.

Hazelrigg and Garnier (1976) found the natural logarithm of per capita energy consumption to be positively associated with total circulation (as indicated by "circulation I"); however, they found no relationship between energy consumption and total openness (as indexed by "circulation II"). Examining the degree to which education mediated the father-son association in occupation, they found the partial associations between fathers' and sons' occupations, controlling for the sons' educations, were negatively associated with nationa energy consumption. 
Hardy and Hazelrigg (1978) found total circulation to be positively related to national rates of educational enrollment, levels of mass communication, urbanization, geographic mobility, per capita expenditures for education, and ethnic-linguistic homogeneity. However, none of these relationships were significant net of national differences in per capita energy consumption. Total openness was not found to be associated with any of these variables, even on the bivariate level. Hardy and Hazelrigg were led to conclude that the important effects of economic development on mobility operated almost entirely through structural differences rather than through differences in openness. This conclusion, that there was no relationship between development and openness, conflicted with both Cutright's (1968a) earlier findings and those of a more recent study.

Adding to the previously compared tables a couple tables from national surveys conducted in the $1970 \mathrm{~s}$, plus tables from several urban samples, Tyree et al. (1979) accumulated mobility data for twenty-four countries. Excluding the rural or farm populations, they found openness between the nonmanual and manual strata to be positively associated with per capita GNP. They also found openness across the nonmanual-manual boundary to be positively associated with both income inequality and the proportion of the labor force holding salaried nonmanual occupations; and, when openness was regressed on both per capita GNP and either equality or the proportion of persons in salaried nonmanual positions, GNP had the smallest effect. These finding led them to speculate that either the relationship between per capita GNP and openness is spurious (explained by the association of both with equality), or equality is an intervening variable mediating the effects of GNP on openness.

How do we reconcile the findings of Cutright (1968a) and Tyree et al. (1979) that openness is associated with economic development, with Hazelrigg's and his colleagues' conclusion that it is not? McClendon (1980a, $1980 \mathrm{~b}$ ) reanalyzed the same set of tables used by Hazelrigg and Garnier (1976), and demonstrated that these differences in conclusions were due to differences in the specific forms of openness examined. Openness between the nonmanual and industrial manual strata was positively associated with development-related variables; but, inheritance for the agricultural manual stratum, involving openness between this stratum and both the nonmanual and industrial manual strata, was slightly negatively associated with development. Thus, the sum or average of all kinds of openness showed very little association with development related variables (McClendon, 1980a). Evidently, industrialization is related to total mobility through its relationships to both structure and some aspects of openness.

How great are the relative contributions of structural differences and differences in openness to the cross-national differences in total mobility? Using his sample of seventeen national mobility tables, McClendon (1980b) regressed total mobility on measures of structural discrepancies, composition, and openness. He found structural differences and differences in openness to ex- 
plain approximately equal proportions of the variance in total mobility. The variables most strongly related to total mobility were the discrepancy effect involving origin-destination differences in the proportion in agricultural occupations, and the composition effect related to the proportion of cases in agriculture. The individual effects of white-collar and blue-collar inheritance were somewhat less strong, but together they explained as much of the variance as did the structural variables. McClendon's sample included only a couple of less industrialized countries, and undoubtedly the effects of structural factors would have been much greater had nations representing a wider range of development been included. Nevertheless, he showed that structural factors are not the only important determinants of cross-national differences in total mobility.

It can be concluded that while this series of cross-national studies has tested only the grossest implications of the industrialization-mobility arguments, and while the data involved such problems of comparability that the parameters are undoubtedly imprecise, the general conclusions reached have been consistent. Total mobility, upward mobility, total circulation, and openness between the nonmanual and manual strata all seem to be positively associated with indicators of industrialization and economic development. Roughly in order of importance, those development-related variables showing the strongest relationships with these aspects of mobility seem to be rates of educational enrollment, economic equality, the proportion of the labor force in nonmanual positions, per capita GNP, per capita energy consumption, urbanization, the proportion of the labor force in agriculture, and the extent of mass communications.

There is some, albeit tenuous, evidence that economic development is associated with the degree to which the relationship between fathers' and sons' occupations is mediated by the sons' educations (Hazelrigg and Garnier, 1976). The few more detailed comparisons of social mobility and status attainment, involving data from two to four countries, are consistent with this conclusion (Lin and Yauger, 1975; Yauger and Lin, 1973; Hansen and Haller, 1977; Treiman and Terrell, 1975; Erikson et al., 1979).

In short, the cross-sectional comparative data are generally consistent with the expected industrialization-mobility relationship. Furthermore, these comparisons partially illuminate how industrialization is related to mobility by indicating the importance of different forms of structural differences and differences in openness. Nevertheless, these comparisons have only dealt with the grossest aspects of mobility, and the cross-sectional evidence cannot prove the existence of the suggested longitudinal relationship.

\section{Socialist-Non-Socialist Differences in Mobility}

Obviously, in both capitalist and socialist societies the positions of fathers and their sons are associated-but not perfectly associated. However, in 
general, the available data have not been adequate for making precise crossnational comparisons of the degree of association. The data for the U.S.S.R. utilized in the comparisons by Lipset and Zetterberg (1957) were obtained from a sample of emigrés, not a sample of the Soviet population. Both the Hungarian mobility table used in the comparison by Miller (1960) and the Bulgarian table used by Hazelrigg and Garnier (1976) included both men and women, but were compared with tables from other nations that included only males. In addition, in the Hungarian mobility tables used in these comparisons, the temporal reference of the respondents' fathers' occupations differed from that in the tables from the other countries. The Polish tables used by Tyree, et al. (1979) were based on a sample of the populations of three cities, yet were compared to the tables for other countries based on national samples. The Romanian table used by Connor (1979) was based on samples of only Bucharest and one village. This list of problems of comparability could be continued. In brief, the cross-national differences in measurement have usually been great enough to make only the grossest comparisons possible, and even these comparisons have been of questionable validity.

Now, as data from the most recent series of mobility surveys have become available (Andorka and Zagorski, 1979), there has been a great improvement in the accuracy with which we can describe nonsocialist-socialist differences, differences among some of the socialist countries, and changes in these countries over time. In some ways, the research on historical changes in mobility in Hungary and Poland surpasses that done in western nations in terms of scope and sophistication. Connor (1979) recently made use of the earliest published results from these surveys and provided the first extensive socialist-nonsocialist comparisons. He concluded that social mobility has increased under socialism, but that similar increases could have occurred under capitalist development. Following the earlier argument of Ossowski (1957), he attributed most of the change in social mobility in the countries of Eastern Europe to the post-war increases in the rates of structural change. Apart from the changes required by shifts in the occupational structure, Connor minimized the effects of postwar changes in social organization and policy on the relative odds of attainment.

In regard to East-West differences in mobility, Connor suggested that with the exception of the greater recruitment of workers into the political elite in Eastern Europe, the data do not support an argument that equality of attainment is presently greater in Eastern Europe than in Western Europe. In fact, he suggested that there may be "marginal advantages in equality of opportunity, narrowly defined, in the West." Connor's conclusions about the great importance of structural influences on the post-war rates of mobility in Eastern Europe are undoubtedly true. However, the cross-national data compared by Connor share some of the same problems of comparability possessed by earlier cross-national studies. This, and the fact that the mobility measures used in his comparisons confounded the effects of differences in structure with differences in relative opportunities, throws into question his conclusions regarding crossnational differences in equality of opportunity. 
In a Polish-American comparison, Meyer et al. (1979) pointed out that the relatively large proportion of persons in agricultural occupations in Poland contributes to the father-son association in status being higher in Poland than in the United States. The close connection between education and occupational position in a planned economy was also pointed out as a contributing factor in intergenerational status inheritance in Poland. We would expect these relationships to affect other socialist-nonsocialist comparisons as well.

Another analysis of intergenerational mobility in Eastern Europe (Simkus, 1980), taking advantage of the most recently made available data and concentrating on specific aspects of mobility, came to different conclusions from those of Connor (1979). Openness between the nonmanual and industrial manual strata in Eastern Europe was found to be about equal to that in the most open West European societies; and, after controlling for levels of economic development, such openness was grcatest in the Eastern European countries. Openness between the industrial-manual and agricultural-manual strata appeared to be exceptionally great in Eastern Europe, but only in those countries with predominantly collectivized agriculture. Such openness in Poland and Yugoslavia, where agricultural production has not been collectivized, was about equal to that in the United States (Simkus, 1980).

Consistent with the arguments of Connor (1979), Ossowski (1957), and others, mobility due to origin-destination structural discrepancies was found to be unusually, but not uniquely, high in the East European countries. The levels of such mobility in Eastern Europe appeared to be not too different from those in such countries as Italy, and equaled or surpassed by such mobility in Japan (Simkus, 1980).

\section{Conclusions Regarding Cross-National Differences in Mobility}

We can summarize the findings regarding cross-national differences in mobility as follows:

1. The total rate of mobility is affected by the evenness of the distribution of persons across social strata, the proportion of the population with agricultural origins or destinations, discrepancies between origin and destination distributions, and the degrees of white collar and farm inheritance (McClendon, 1980a, 1980b).

2. Mobility due to origin-destination discrepancies is closely associated with rates of structural change and appears to have been greatest in Japan and certain East European countries (Ossowski, 1957; Connor, 1979; Simkus, 1980).

3. Openness between the nonmanual and industrial-manual strata is positively correlated with economic development (Cutright, 1968a; McClendon, 1980a; Tyree et al., 1979), income inequality, immigration 
and the proportion of the labor force in salaried nonmanual positions (Tyree et al., 1979), and state socialist policies in Eastern Europe (Simkus, 1980).

4. Status attainment models and mobility tables indicate that 1) the direct effect of social origin on social destination is positively associated with industrialization (Lin and Yauger, 1975; Meyer et al., 1979; Hazelrigg and Garnier, 1976), 2) the effect of education on occupational status may be unusually great under state socialism (Meyer et al., 1979), and 3 ) the effect of education on destination may be greater in Poland and Great Britain than in the United States (Meyer et al., 1979; Treiman and Terrell, 1975).

No doubt, these comparative studies of mobility provide evidence in an area where speculation has been common. Nevertheless, there are serious problems with this evidence. First, there are very great problems of comparability between the national tables compared. The same sorts of criticisms which were made of the socialist-nonsocialist comparisons can be applied to the other comparisons. Definitions of social strata, social origins, and sampled populations are disturbingly inconsistent among these tables. Second, some aspects of mobility in these tables are highly subject to sampling error, and in multivariate analyses of 10-20 national tables, inaccurate outliers can have great effects on estimated parameters.

Third, historical changes in mobility regimes resulting in cross-cohort differences in mobility confound cross-national comparisons based on aggregate data (Burrawoy, 1977). While it is true that longitudinal trends in openness in some western countries have shown little change (Treiman, 1977), total mobility and openness in some radically changing societies have been subject to substantial changes.

Fourth, status attainment models utilizing synthetic status scales and mobility tables based on gross 3-category occupational schemes obscure important relationships between structural change and shifts in mobility (Burawoy, 1977). Fifth, while the scarcity of comparisons including women can hardly be blamed on those conducting secondary analyses when the primary data are so limited, these gender related limitations on our knowledge prevent us from answering questions both important and interesting (Burrawoy, 1977; Treiman 1977).

Finally, in regard to multivariate analyses of differences among sets of ten to twenty national mobility tables, Galton's problem is so severe that conclusions should be considered tentative and the use of tests of significance in hypothesis testing seems unreasonable. The samples of countries for which data are available are in no way representative samples from the relevant universe; and, the assumption of independence between cases is violated in a particularly poignant manner when some of these countries have influenced others through political, economic, or military domination. 


\section{Other Topics of Comparison}

While there were relatively few comparative studies of the relational aspects of social stratification, there were important studies of agrarian class relations (Paige, 1975; Stavenhagen, 1975), and there were studies of the relationships between social classes and various forms of political behavior (Abramson, 1971, 1973; Sito, 1971; Segal, 1967). Analyses of specific classes and occupational strata also dealt with class relations (Form, 1969, 1976; Spenner, 1975; Frank, 1972). Comparative analyses of social networks and patterns of differential association (Laumann, 1966; Laumann and Pappi, 1975) could contribute much to a more precise understanding of cross-national differences in cross-class interaction on the individual level, but hardly any such comparisons have been carried out. Apart from these quantitative studies, a number of theoretical discussions of class relations (Giddens, 1973; Parkin, 1971) have included comparisons based on crude aggregate data or descriptive accounts.

Even though the number of comparisons has not approached that characterizing studies of occupational prestige and mobility, there have been a variety of studies of the social-psychological correlates of stratification. These have included studies of social distances between occupations (Laumann and Senter, 1976), perceptions of class divisions and justice (Vanneman, 1980; Robinson and Bell, 1978), and class differences in values and orientations (Jeffries et al., 1979; Simpson, 1970).

There have been only a few comparisons of such phenomena as patterns of class-based assortative marriage (Connor, 1976; Kerckhoff, 1978) and residential segregation (Rhodes, 1969). Other areas in which there have been only scatttered studies include comparisons of inequalities in cities (Balan, 1969), migration and social mobility (Bock and Iutaka, 1969), wealth and family background (Kelly, 1978), and the relationship between family types and stratification (Chu and Hollingsworth, 1969). Considerably more research on the relationships between stratification and such institutions as the family needs to be done. Cross-national comparisons dealing with a variety of dimensions of society simultaneously may help extend our understanding of the relationships between stratification and other aspects of social organization (Allardt and Wesolowski, 1978).

\section{Conclusions and Prospects}

Comparative research on social stratification in the 1970s reflected the application of the theoretical and methodological contributions of the $1960 \mathrm{~s}$ to data available from a progressively wider set of societies. The distribution of these studies across subject areas was fairly lopsided. Most studies were concentrated in the areas of income inequality, occupational prestige, and social mobility. In part, this situation reflected interest in these topics. It also 
reflected the greater availability of data related to these topics for secondary analyses. Also important was the degree of support given international collaboration in these areas by such organizations as the International Sociological Association.

Many of the contributions involved the extension of comparisons based on fairly simple aggregate data to a progressively growing sample of countries. Descriptions of the correlates of cross-national differences in inequality and mobility improved; and, research concerned with cross-national similarities in occupational prestige culminated in a major statement and analysis of the accumulated comparative data. In the near future, comparisons based on the large-scale national mobility surveys of the mid-1970s will involve unprecedented comparability, reliability, and detail. For the first time, comparative analyses of mobility may involve the same levels of elegance and detail characterizing studies of mobility in single societies.

Unfortunately, many subjects which have contributed to within-society descriptions of stratification were relatively ignored as topics for cross-national comparisons. The set of countries compared was also restricted-many comparisons involved the nations of Europe and North America, and far fewer involved the societies of Asia, Africa (Southall, 1970), and South America. Even more serious was the gap between theoretical analyses of structured class relations and quantitative comparisons of inequality and mobility. This gap need not be as great as it has been (Wesolowski, et al., 1979). This gap has been partly due to the inadequacies of the available comparative data; however, it has also been due to the incongruence between the conflict group model of stratification involved in analyses of class relations and the inegalitarianclassless model implied in the methods of many comparative studies. Recent studies, such as those by Vanneman (1980), Erikson et al. (1980), and Andorka and Zagorski (1979), exemplify alternatives to analyses based on a continuous conception of stratification, and describe of relationships among discrete classes, status groups, and strata. Studies of the relational and distributional aspects of stratification are far more likely to mutually inform each other when they share the same basic units of analysis.

\section{REFERENCES}

Abramson, Paul R.

1971 "Social class and political change in Western Europe: A cross-national longitudinal analysis." Comparative Political Studies 4 (July): 131-155.

1973 "Intergenerational social mobility and partisan preference in Britain and Italy: A cross-national comparison." Comparative Political Studies 6 (July): 221-234.

Allardt, Erik, and Włodzimierz Wesolowski, Eds.

1973 Social Structure and Change: Finland and Poland Comparative Perspective. Warsaw: Polish Scientific Publishers.

Andorka, Rudolf, and Krzysztof Zagórski

1979 A Társadalmi Mobilitás Magyarországon és Lengyelországban (Social Mobility in Hungary and Poland). Budapest: Központi Statisztikai Hivatal. 
Armer, J. Michael

1968 "Intersociety and intrasociety correlations of occupational prestige." American Journal of Sociology 74 (July): 28-36.

Balán, Jorge

1969 "Diferencias Socioeconómicas en las Ciudades Latino-americanas: Un Estudio Fstructural (Socioeconomic differences in Latin American Cities: A structural study)." Desarrollo Economico 9 (October-December): 399-431.

Bardis, Panos D.

1967 "Slavery in five major civilizations." Sociological Bulletin 16 (March): 50-61.

Blau, Peter M., and Otis Dudley Duncan

1967 The American Occupational Structure. New York: John Wiley and Sons.

Bock, W. Wilbur, and Sugiyama Iutaka

1969 "Rural-urban migration and social mobility: the controversy on Latin America." Rural Sociology 34 (September): 343-355.

Boudon, Ramond

1973 Mathematical Structures of Mobility. San Francisco: Jossey-Bass.

1974 Education, Opportunity, and Social Inequality: Changing Prospects in Western Society. New York: Wiley.

Boyd, M., David L. Featherman, and J. Matras

1981 "Status attainment of immigrant and immigrant origin groups in the United States, Canada, and Israel." Comparative Studies in Sociology 3 (forthcoming).

Broom, Leonard, and F. Lancaster Jones

1969a "Father to son mobility: Australia in comparative perspective." American Journal of Sociology 74 (January): 333-342.

1969b "Career mobility in three societies: Australia, Italy, and the United States." American Sociological Review 34 (October): 650-658.

Broom, Leonard, and Patrick McDonnell

1974 "Current research on social mobility: An inventory." Current Sociology 22: 353-391.

Burawoy, Michael

1977 "Social structure, homogenization, and the process of status attainment in the United States and Great Britain." American Joumal of Sociology 82 (March): $1031-1042$.

Chu, Hsien-jen, and J. Hollingsworth

1969 "A cross-cultural study of the relationships between family types and social stratification." Journal of Marriage and the Family 31 (May): 322-327.

Connor, Walter D.

1979 Socialism, Politics, and Equality: Hierarchy and Change in Eastern Europe and the U.S.S.R. New York: Columbia University Press.

Cutright, Phillips

1968a "Occupational inheritance: A cross-national analysis." American Journal of Sociology 72 (January): 400-416.

1968b "Studying cross-national mobility rates." Acta Sociologica 11: 170-176.

Das, Man Singh

1971 "Economic aspects of caste in India and the United States." Social Science 46 (October): 232-237.

DeGre, Gerard

1974 "Realignments of class attitudes in the military and bourgeoisie in developing countries: Egypt, Peru, and Cuba." International Journal of Comparative Sociology 15 (MarchJune): $35-46$

Duncan, Otis Dudley

1979 "How destination depends on origin in the occupational mobility table." American Journal of Sociology 84: 793-803.

Erikson, Robert, John Goldthorpe, and Lucienne Portocareco,

1979 "Intergenerational class mobility in three Western European societies: England, France, and Sweden." British Journal of Sociology 30. 
Featherman, David L., Robert M. Hauser, and William H. Sewell

1974 "Toward comparable data on inequality and stratification: Perspectives on the second gencration of national mobility studies." The American Sociological Review 9 (February): 18-25.

Featherman, David L., F. Lancaster Jones, and Robert M. Hauser

1975 "Assumptions of social mobility research in the U.S.: the case of occupational status." Social Science Research 4 (December): 329-360.

Form, William $\mathrm{H}$.

1969 "Occupational and social integration of automobile workers in four countries: A comparative study." International Journal of Comparative Sociology 10 (March-June): 95-116.

1976 Blue-Collar Stratification. Princeton: Princeton University Press.

Fox, Thomas G., and S. M. Miller

1965a "Economic, political, and social determinants of mobility: an international crossnational analysis." Acta Sociologica 9: 76-93.

1965b "Occupational stratification and mobility: Intra-country variations." Studies in ComFrank, A. G. parative International Development. Original Series 001: 1-10.

1972 Lumpenbourgeoise: Lumpendevelopment, Dependence, Class and Politics in Latin America. M. D. Berdecio, trans. New York: Monthly Review Press.

Garnier, Maurice, and Lawrence Hazelrigg

1974 "La mobilité professionelle en France comparie a celle d'autres pays." (The extent of occupational mobility in France compared with other countries). Revue Française de Sociologie 15 (July-September): 363-378.

Giddens, A.

1973 The Class Structure of Advanced Societies. New York: Barnes \& Nobel.

Goldthorpe, John H.

1964 "Social stratification in industrial society." In The Development of Industrial Society, Paul Halmos (ed.), The Sociological Review, Monograph No. 8.

Goodman, Leo A.

1969 "How to ransack social mobility tables and other kinds of class-classification tables." American Journal of Sociology 75: 1-39.

1972 "Some multiplicative models for the analysis of cross-classified data." Pp. 649-696 in Proceedings of the Sixth Berkely Symposium on Mathematical Statistics and Probability. Berkely: University of California Press.

1979 "Multiplicative models for the analysis of occupational mobility tables and other kinds of cross-classification tables." American Journal of Sociology 84: 804-819.

Haller, Archibald O., and David B. Bills

1979 "Occupational prestige hierarchies: Theory and evidence." Contemporary Sociology 8 (September): 721-734.

Hansen, David O

1977 "Age variations in the formation of educational and occupational career goals of Brazilian youth: A cross-cultural test of the Wisconsin model." Comparative Education Review 21 (February): 37-50.

Hansen, David O., and Archibald O. Haller

1977 'On Lin and Yauger's cross-national comparison of the process of occupational status achievement." American Journal of Sociology 82, 4 (January): 854-857.

Hardy, Melissa, and Lawrence E. Hazelrigg

1978 "Industrialization and the circulatory rate of mobility: further tests of some crosssectional hypotheses." Sociological Focus 11: 1-10.

Harris, Edward E.

1968 "The generalizability of prestige in cross-cultural perspective: theoretical and methodological comments." Australian and New Zealand Journal of Sociology 4 (April): 63-67. 
Hauser, Robert M.

1977 "A structural model of the mobility table." CDE Working Paper 77-13, Center for Demography and Ecology, Madison, Wisconsin.

Hauser, Robert M., Peter J. Dickinson, Harry P. Travis, and John M. Koffel

1975 "Temporal change in occupational mobility: evidence among men in the United States." American Sociological Review 40: 585-598.

Hazelrigg, Lawrence $\mathrm{E}$.

1974 "Cross-national comparisons of father-to-son occupational mobility." In J. Lopreato and L. S. Lewis (eds.), Social Stratification: A Reader. New York: Harper and Row.

Hazelrigg, Lawrence E., and Maurice A. Garnier

1976 "Occupational mobility in industrial societies: a comparative analysis of differential access to occupational ranks in seventeen countries." American Sociological Review 41 (June): 498-510.

Hewitt, Christopher

1977 "The effect of political democracy and social democracy on equality in industrial societies: a cross-national comparison." American Sociological Review 42: 450-64.

Jakubowicz, C.

1968 "Comparative studies of occupational hierarchies." Co-Existence 5 (January): 63-84.

Jeffries, Vincent, Robert T. Morris, and David R. Schweitzer

1979 "Social class and values." International Journal of Comparative Sociology 20 (SeptemberDecember): 224-240.

Jones, Frank E.

1976 "Social origins in four professions: A comparative study." International Journal of Comparative Sociology 17 (September-December): 143-163.

Jones, F. Lancaster

1969 "Social mobility and industrial society: a thesis re-examined." Sociological Quarterly 10 (Summer): 292-305.

1971 "Occupational achievement in Australia and the United States: A comparative path analysis." American Journal of Sociology 77 (November): 527-539.

Jones, F. Lancaster, and Patrick McDowell

1977 "Measurement of occupational status in comparative analysis: A research note." Sociological Methods and Research 5 (May): 427-459.

Kalleberg, Arne L., and Aage B. Sorensen

1979 "The sociology of labor markets." In Annual Review of Sociology 5, Alex Inkeles, James Coleman, and Ralph Turner (eds.), Palo Alto: Annual Reviews.

Kelley, Jonathan

1978 "Wealth and family background in the occupational career: theory and cross" cultural data." The British Journal of Sociology 29 (March): 94-109.

Kerckhoff, Alan C.

1974 "Stratification processes and outcomes in England and the U.S." American Sociological Review 39 (December): 789-801.

1978 "Marriage occupational attainment in Great Britain and the United States." Journal of Marriage and the Family 40 (August): 595-599.

Kleining, G.

1978 "Preliminary results from comparative countries." Paper presented to the IX World

Lane, David Congress of Sociology, Uppsala, August.

1971 The End of Inequality? Stratification Under State Socialism. Hammondsworth: Penguin Books Ltd.

1976 The Socialist Industrial State. London: George Allen and Unwin.

Laumann, E. O.

1966 Prestige and Association in an Urban Community: An Analysis of an Urban Stratification System. Indianapolis: Bobbs-Merrill 
Laumann, Edward O., and Richard Senter

1976 "Subjective social distance, occupational stratification, and forms of status and class consciousness: A cross-national replication and extension." American Journal of Sociology 81 (May): 1304-38.

Lenski, Gerhard E.

1966 Power and Privilege: A Theory of Social Stratification. New York: McGraw-Hill.

Lin, Nan, and Daniel Yauger

1975 "The process of occupational status achievement: A preliminary cross-national comparison." American Journal of Sociology 81 (November): 543-562.

Lipset, S. M., and Hans L. Zetterberg

1957 "Social mobility in industrial societies." Pp. 12.75 in Seymour Martin Lipset and Reinhard Bendix, Social Mobility in Industrial Society. Berkeley: University of California Press.

Matras, Judah

1980 "Comparative social mobility." In Annual Review of Sociology. Palo Alto: Annual Reviews (forthcoming).

McCann, James C.

1977 "A theoretical model for the interpretation of tables of social mobility," American Sociological Review 42 (February): 74-90.

McClendon, McKee J.

1980a "Occupational mobility and economic development: a cross-national analysis." Sociological Focus (forthcoming).

1980b "Structural and exchange components of occupational mobility: A cross-national analysis." Sociological Quarterly (forthcoming)

McRoberts, H. A., and K. Selbee

1978 "Trends in occupational mobility in Canada and the United States: a comparison." Paper presented to the IX World Congress of Sociology, Uppsala, August.

Meyer, John W., Nancy Brandon Tuma, and Krzysztof Zagórski

1979 "Education and occupational mobility: a comparison of Polish and American men."

Miller, S. M. American Journal of Sociology 84 (January): 978-986.

1960 "Comparative social mobility." Current Sociology 9: 1-89.

Miller, S. M., and H. J. Bryce

1961 "Social mobility and economic growth and structure." Kölner Zeitschrift für Soziologie 13: 303-315.

Moots, Baron L.

1976 "Migration, community of origin, and status attainment: A comparison of two metropolitan communities in developing societies." Social Forces 54 (June): 816-832.

Ossowski, Stanislaw

1957 "Social mobility brought about by social revolution." Working paper, Fourth Working Conference on Social Stratification and Social Mobility, International Sociological Association, Geneva.

Paige, Jeffery M.

1975 Agrarian Revolulion: Social Movements and Export Agriculture in the Underdeveloped World. New York: Macmillan.

Parkin, Frank

1969 "Class stratification in socialist societies." British Journal of Sociology 20 (December): 355-374.

1971 Class Inequality and Political Order: Social Stratification in Captialist and Communist Societies. New York: Praeger.

Pöntinen, Seppo

1976 Patterns of Social Mobility in the Scandinavian Countries. Licentiate Thesis, University of Helsinki. 
Pryor, Frederic L.

1968 Public Expenditures in Communist and Capitalist Nations. London: Allen \& Ulwin.

1971 Economic System and the Size Distribution of Income and Wealth. Bloomington: International Development Research Center, Indiana University.

1972 "The distribution of non-agricultural labor incomes in communist and capitalist nations." Slavic Review 31 (September): 639-650.

1973 Property and Industrial Organization in Communist and Capitalist Nations. Bloomington: Indiana University Press.

Pullum, Thomas $W$.

1975 Measuring Occupational Inheritance. New York: Elsevier.

Rhodes, A. Lewis

1969 "Residential distribution and occupational stratification in Paris and Chicago." Sociological Quarterly 10 (Winter): 106-112.

Robinson, Robert V., and Wendell Bell

1978 "Equality, success, and social justice in England and the United States." American Sociological Review 43 (April): 125-143.

Segal, David R.

1967 "Classes, strata, and parties in W. Germany and the United States." Comparative Studies in Society and History 10 (October): 66-84.

Siegel, Paul, and Robert Cole

1980 "Returns to alternative job-changing patterns: a Detroit-Yokohama comparison." Paper delivered at the Japan-U.S. Conference on Social Stratification and Mobility, January 3-7, Hawaii.

Simkus, Albert A.

1980 "Social mobility in the Socialist countries of Eastem Europe: Processes and parameters." Paper presented at the annual meeting of the Population Association of America, April, Denver, Colorado.

Simpson, Miles E.

1970 "Social mobility, normlessness, and powerlessness in two cultural contexts."

Sito, Nilda American Sociological Review 35 (December): 1002-1013.

1971 "Estructura occupacional, desarrollo y sindicalismo en los paises Latioamericanos." (Occupational structure, development, and syndicalism in Latin American countries). Revista Latioamericana de Sociologia 7: 6-36.

Southall, Aidan W.

1970 "Stratification in Africa." In Essays in Comparative Social Stratification. Leonard Plotnicor and Arthur Tuden (eds.), Pittsburgh: University of Pittsburg Press.

Spenner, Kenneth I.

1975 "The internal stratification of the working class: A reanalysis." American Sociological Review 40 (August): 513-520.

Stavenhagen, Rodolfo

1975 Social Classes in Agrarian Sacieties. Judy Adler Hellman (trans.), New York: Anchor Books.

Svalastoga, Kaare

1965 "Social mobility: the Western European model." Acta Sociologica 9: 175-182.

Svalastoga, Kaare, and Tom Rishoj

1970 "Western European mobility." American Journal of Sociology 76 (November): 520-523.

Teckenberg, Wolfgang

1977 "Prestigerangordnungen, berufliche Bewertungen and Präferenzen in der USSR im internationalen Vergleich." (Prestige ratings, occupational evaluation and preference in the U.S.S.R. in international comparisons). Kölner Zeitschrift für Soziologie and Sozialpsychologie 29 (December): 731-761.

Tilly, Charles, Louise Tilly, and Richard Tilly

1975 The Rebellious Century, 1830-1930. Cambridge: Harvard University Press. 
Treiman, Donald J.

1970 "Industrialization and social stratification." Sociological Inquiry 40 (Spring): 207-234.

1975 "Problems of concept and measurement in the comparative study of occupational mobility." Social Science Research 4 (September): 183-230.

1976 "Standard occupational prestige scale for use with historical data." The Volume of Interdisciplinary History 7 (Autumn): 283-304.

1977 "Towards methods for a quantitative comparative sociology: a reply to Burawoy." American Journal of Sociology 82 (March): 1042-1056.

1979 Occupational Prestige in Comparative Perspective. New York: Academic Press.

Treiman, Donald J., and Kermit Terrell

1975 "The process of status attainment in the United States and Great Britain." American Journal of Sociology 81 (November): 563-82.

Tyree, Andrea, Moshe Semyonoy, and Robert W. Hodge

1979 "Gaps and glissandos: Inequality, economic development, and social mobility in 24 countries." American Sociological Review 44 (June): 410-424.

Uusitalo, Hannu J.

1973 "A note about the stratification aspects of a comparative survey in four Nordic countries." Social Science Information 12 (August): 45-50.

Vanneman, Reeve D.

1980 "U.S. and British perceptions of class." American Journal of Sociology 85: 769-790.

Wesolowski, Wlodzimierz, Slomczynski Kazimierz M., and Mach, Bogdan W. (eds.)

1978 Social Mobility in Comparative Perspective. Warsaw, Polish Academy of Sciences Press.

1979 "Trends in social mobility studies and Marxist theory of class structure." The Polish Sociological Bulletin 1: 5-18.

Yasuda, Saburo

1964 "A methodological inquiry into social mobility." American Sociological Review 29: 16-23.

Yauger, D., and Nan Lin

1973 Economic Development and Occupational Stratification: A Preliminary Cross-National Comparison. International Center for Social Research, State University of New York at Albany. 